\title{
O desenvolvimento de elementos de proteção de fachada responsivos: explorando o cobogó
}

\author{
Developing a responsive system for building façade protection using the cobogó as reference \\ - Hugo Rodrigues de Souza Pinto \\ UFPE, Brazil \\ hugordsp@gmail.com \\ Adriano Rodrigo Barreto Cardoso \\ UFPE, Brazil \\ adrianoarbc@gmail.com \\ - Natália Queiroz \\ UFPE, Brazil \\ nataliaqueiroz.arq@gmail.com \\ Joana Pack Melo Sousa \\ UFPE, Brazil \\ joanapacksousa@gmail.com
}

\begin{abstract}
The goal of this paper is to present the results of a research that seeks to develop a responsive system for building façade protection using as reference the cobogó. This element was created to protected interior environment from direct sun light and provide good ventilation. The paper will present the process, different prototypes, methodologies and software used along the research. In future work we will test different algorithms to make the system responsive not only to environmental factors but to human activities.
\end{abstract}

Keywords: Façade Protection, Cobogó, Responsive Architecture

\section{Introdução}

O desenvolvimento de anteparos para a proteção de fachadas e otimização do conforto ambiental em espaços internos, apresenta uma longa história. Exemplos podem ser identificados em painéis de portas e janelas chinesas, em painéis Muxarabis islâmicos ou no brise soleil, amplamente utilizado na arquitetura moderna (Souza, 2012). Além destes, outro importante componente construtivo, criado para regular o conforto nos diferentes ambientes de uma construção, é o cobogó.

Segundo Vieira, Borba e Rodrigues (2012) o cobogó foi inventado por dois comerciantes e um engenheiro radicados no Recife no início do século XX - Coimbra, Boeckmann e Góes. O cobogó - iniciais dos sobrenomes para batizar o produto - foi inicialmente concebido como um simples elemento pré-fabricado, próprio para ser construído em série, baseado em uma retícula vazada sobre uma placa prismática de concreto. Conforme os autores, na prática, se utilizado como elemento de composição de septos verticais, o elemento permite a passagem da ventilação natural, ao mesmo tempo em que reduz a incidência da luz solar, características que os adequam para projetos em lugares de clima quente e úmido.

Segundo Oliveira (2002), o cobogó tem função semelhante à dos antigos muxarabi de madeira, também resgatados pela arquitetura moderna. Estes podem funcionar como filtros solares e visuais, apresentando assim atributos semelhantes aos ripados de madeira, porém com a vantagem de possibilitar a criação de grandes planos leves e permeáveis. Pode ser citada como referência do uso cobogó, criando uma textura uniforme na fachada a Caixa d'água de Olinda, de Luiz Nunes, construída em 1936. A autora afirma que apesar da volumetria da edificação, de geometria simples, contrastar com o ambiente urbano em que foi construída, a obra teve destaque no número especial sobre o Brasil da revista inglesa The Architectural Review, em 1944, como representante de um diálogo entre tradição e modernidade. Vieira et. al. (2012) explicam que o cobogó, na caixa d'água de Olinda, foi utilizado com a função de "quebra-sol", que auxiliava na amenização do calor, incidente nas tubulações, preservando e resfriando também a temperatura das águas acumuladas no tanque superiores.

Assim como o brise soilel, o cobogó foi largamente aplicado na arquitetura brasileira durante o século $\mathrm{XX}$, sendo possível identificar sua presença não apenas em obras que podem ser consideradas referências da arquitetura brasileira. Atualmente, apesar do cobogó ainda estar presente em diversas edificações, este tem sido gradativamente substituído pelos sistemas de condicionamento de ar mecânico, que apresentam um alto grau de consumo energético. Contudo, as crescentes preocupações com questões relacionadas à sustentabilidade estão promovendo cada vez mais pesquisas que visam identificar soluções alternativas que possibilitem a redução do consumo energético ao longo da vida útil do edifício.

Atualmente, inúmeros projetistas aplicam princípios de 
automação com o objetivo de criar edifícios que respondam a diferentes estímulos ambientais. Este conceito tem origem no trabalho de Negroponte (1975), que descreve a arquitetura responsiva como sendo o produto natural da integração da computação com a arquitetura para a produção de espaços ou estruturas otimizadas. Segundo o autor, o início de pesquisas na área foi um reflexo da crise na arquitetura racionalista e da interminável repetição de formas da arquitetura industrializada. O objetivo era criar um espaço inteligente que respondesse às exigências dos usuários.

Em diferentes projetos arquitetônicos é possível identificar soluções baseadas na automação do edifício ou de suas partes para promover a adequada insolação e permitir a optimização de processos de ventilação. D’alecon (2013), define as fachadas inteligentes ou responsiva como aquelas que têm a capacidade de se adaptar às condições do ambiente, graças a um sistema que integra dados sobre a performance do edifício, uma modelagem ou avaliação deste desempenho e sistemas de controle permanente para corrigir e adequar o ambiente construído ao clima e uso. Os elementos típicos que fazem parte dessas estratégias são: a regulagem da iluminação natural e artificial segundo condições de nebulosidade e de calefação e de refrigeração segundo a ocupação dos ambientes.

Tanto o SDU Campus Kolding na Dinamarca, projetado pelo escritório de Henning Larsen Architects, quanto as Torres Al Bahar, em Abu Dhabi projetadas pelos arquitetos Aedas, contém uma segunda película na fachada que responde estímulos climáticos. O primeiro é formado por 1600 painéis triangulares perfurados basculantes, enquanto que o segundo foi projetado com inspiração cultural no muxarambi (Archdaily, 2013). Ambos possuem um sistema inovador de sombreamento dinâmico, que se auto ajusta de acordo com o ângulo de incidência e intensidade dos raios solares. As fachadas responsivas têm um conjunto de sensores que determina a regulação individual e automática de cada painel, permitindo a manutenção de condições climáticas ótimas no interior do edifício. (Archdaily, 2015)

O edifício Bad Gleichenberg, projetado por Ernst Giselbrecht and Partner ZT GmbH, construído na Áustria em 2007, também introduz um sistema de fachadas dinâmicas que podem ser adaptados as necessidades dos usuários (E-architect, 2015). O grupo DesignInc projetou em 2006 o prédio da prefeitura de Melbourne o $\mathrm{CH} 2$ (Council House 2) com o objetivo de o tornar o prédio mais sustentável da Austrália. Um dos elementos considerados no projeto foi o desenho de uma fachada de painéis de madeira automatizados que se adaptam as necessidades dos usuários ao longo das quatro estações do ano (Archdaily, 2014).

Este artigo visa apresentar os resultados de uma pesquisa que tem como objetivo desenvolver um elemento de proteção de fachadas responsivo baseado no cobogó voltado para a utilização em climas quentes e úmidos. Cada um destes elementos será controlado por um microcontrolador de placa única que enviará dados para servo motores que posicionam partes do cobogó de modo que seja otimizada a iluminação e ventilação, segundo parâmetros definidos em um algoritmo. Estes componentes deverão funcionar em grupos independentes, possibilitando assim o direcionamento do vento ou o aumento e redução da iluminação segundo a função exercida em um determinado ambiente.

Além de buscar uma alternativa para os sistemas de ar condicionado, a partir do trabalho foi possível simular o processo de desenvolvimento de um componente inteligente, que envolveu em um mesmo trabalho conceitos de modelagem paramétrica, programação, robótica e prototipagem digital. Este foi um processo importante porque a partir dele foi possível avaliar quais seriam as dificuldades enfrentadas para implementar este tipo de conhecimento em um curso de arquitetura, considerando-se não apenas as limitações financeiras de uma instituição de ensino pública, mas a sua tradição de ensino de projeto.

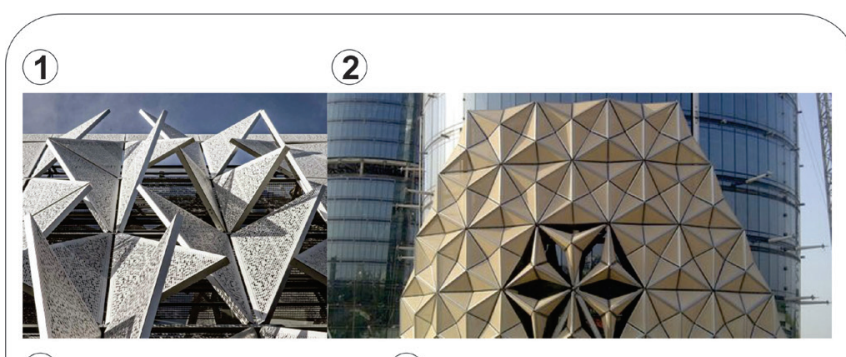

(3)

(4)

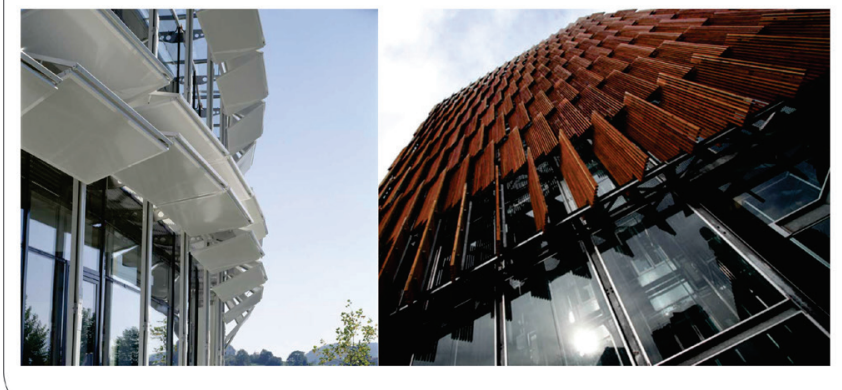

Figura 1: (1) SDU Campus Kolding. (2) Torres Al Bahar. (3) Bad Gleichenberg (4)Council House 2. Fonte: E-architect, 2015, e Archdaily (2013, 2014 e 2015).

\section{Metodologia}

A pesquisa se desenvolveu em seis etapas básicas, cada uma delas tendo como objetivo:

1. Avaliar o uso do cobogó na cidade do Recife: estudar se ainda são utilizados ou como foram utilizados estes elementos de proteção de fachada na cidade do Recife. Caso sejam aplicados, em que situações ocorrem? Estes podem ainda ser utilizados como referência? Como podem ser otimizados?

2. Definir a geometria dos protótipos: explorar diferentes métodos para a geração da forma de modo a equalizar complexidade geométrica e automação do modelo segundo as necessidades ambientais;

3. Elaborar modelos físicos dos protótipos: avaliar diferentes configurações das partes do componente e compreender como suas partes iriam se movimentar; 
4. Analisar os protótipos em um ambiente de modelagem paramétrica e em aplicativos de ventilação e iluminação: testar o componente digital simulando seu funcionamento em relação à parâmetros ambientais;

5. Correlação entre sensores e modelos digitais: avaliar resposta do modelo paramétrico em relação à sensores presentes em situações reais. Três parâmetros foram inicialmente selecionados para avaliação (temperatura, luminosidade e umidade);

6. Elaborar um protótipo funcional: criar um componente de baixo custo que possa ser facilmente reproduzido e diferentes algoritmos testados para avaliar sua eficiência em diferentes cenários.

Cada uma das etapas será descrita em detalhe a seguir.

\section{Etapa 1 - estudo do uso do cobogó}

Como foi explicado, o cobogó foi escolhido como referência para o desenvolvimento do anteparo automatizado. Sendo assim no início da pesquisa foi realizado um levantamento dos diferentes modelos de cobogó utilizados em edificações na cidade do Recife. Durante o período de um mês os pesquisadores buscaram informações sobre diferentes edifícios, sejam estes simbolicamente relevantes ou não, no âmbito da arquitetura Pernambucana. $O$ processo de pesquisa envolveu o levantamento de material bibliográfico e de campo. Para cada uma das situações observadas imagens foram recolhidas para posterior classificação. A partir da análise do material constatou-se que gradativamente houve uma perda da funcionalidade ou substituição destes elementos. Mesmo em edifícios mais antigos, sistemas de condicionamento de ar automatizado foram adicionados, complementando o conforto em ambientes internos.

Em edifícios construídos mais recentemente não é possível verificar mais o uso destes elementos, sendo que o ar-condicionado passou a ser utilizado como principal instrumento parar gerar conforto nos ambientes das edificações. Esta situação reflete no desprezo em relação à implantação das edificações e despreocupação com as fachadas. Na cidade é possível verificar, por exemplo, edifícios com o mesmo projeto construídos segundo diferentes orientações nos terrenos.

Também, observou-se o uso variado destes elementos nas mais diferentes situações, protegendo contra o sol excessivo, permitindo a ventilação e protegendo visualmente ambientes internos. Em alguns casos seu emprego não se relaciona ao conforto e proteção dos ambientes, mas na criação de uma segunda pele, com uma textura diferenciada, contemplando aspectos relacionados à estética das edificações.

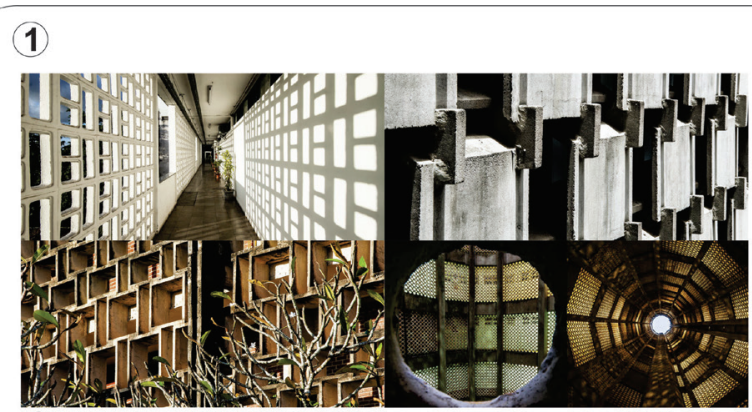

(2)

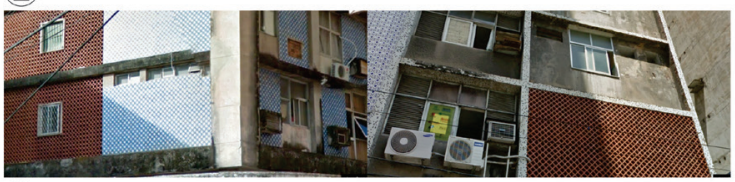

(3)

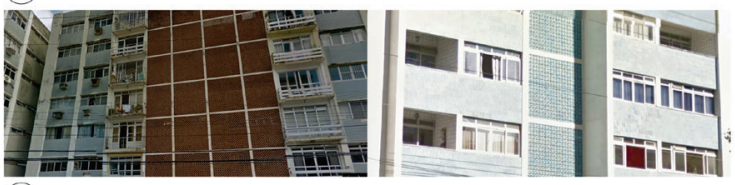

(4)

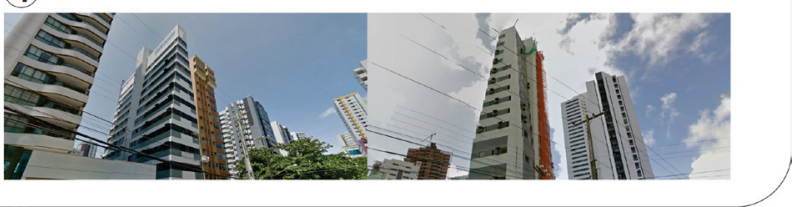

Figura 2: (1) Imagens extraídas de Vieira et. al. (2012) mostrando em detalhe o uso do cobogó em edificações de substancial valor arquitetônico na cidade do Recife. (2) Situações em que o arcondicionado passou a ser utilizado como principal instrumento para adequar ambientes internos. Na imagem à esquerda verifica-se que o cobogó foi retirado em parte da fachada original. (3) Edifícios residências padrões da cidade. Neste caso é possível observar como era corriqueiro o uso de elementos vazados. (4) Exemplo de descaso em relação ao conforto. Edificações contemporâneas, com o mesmo projeto, seguindo diferentes orientações no terreno. Fonte: elaboração própria.

\section{Etapa 2 - Definição da geometria dos protótipos}

Nesta etapa os dados coletados no levantamento foram analisados e definidas as possíveis características geométricas e funcionais que o protótipo deveria ter, fazendo uma correlação comoclima da cidadedo Recife. Oclima da cidadeécaracterizado por ser tropical litorâneo quente e úmido, com temperaturas elevadas ao longo do dia e do ano (média anual de $25,5^{\circ} \mathrm{C}$ ), com uma radiação difusa muito intensa, um alto grau de umidade do ar (média de $80 \%$ e e uma precipitação média anual elevada, sobretudo nos meses de inverno, acima de $2.000 \mathrm{~mm}$ (FREITAS, 2008). Existem dois padrões climáticos durante o ano: a estação seca ou de estiagem, que se prolonga de setembro a fevereiro (primavera-verão), e a estação chuvosa, de março a agosto (outono-inverno) (BARROS E LOMBARDO, 2013). A cidade está 
sob a influência dos ventos alísios do hemisfério austral, com a direção predominante de sudeste e direções secundárias de Sul e de Leste. A velocidade média, segundo o Instituto Nacional de Meteorologia (INMET), é de 2,82 m/s. Como resultado, o protótipo deverá ter as seguintes características:

1. Funções básicas: assim como o cobogó original, uma boa ventilação e funcionar como anteparo de proteção contra a incidência direta do sol;

2. Responsivoà luz:Suas partes deveriam ser moveis, permitindo assim o controle pelo o usuário, segundo as necessidades de luz em relação as atividades a serem desenvolvidas nos ambientes; 3. Responsivo ao vento: em panos de fachada maior, grupos de componentes deveriam trabalhar de modo independente, de modo a permitir o direcionamento do vento para diferentes áreas dos ambientes.

4. Padrões de desenho: os componentes deveriam trabalhar de modo a criar diferentes configurações na fachada, servindo como componente de composição do edifício.

O sistema, portanto, deveria ser controlado de modo a permitir diferentes configurações em relação a ventilação, a presença ou não de luz direta incidindo em suas partes, ou a parâmetros relacionados a umidade e temperatura. Como resultado, inicialmente foram definidos como parâmetros a serem estudados a temperatura, a humidade, e a luminosidade. Como será descrito mais adiante, três sensores foram escolhidos para capturar informações do ambiente: temperatura (LM35), humidade (DHT11), luminosidade (LDR).

A partir destas diretrizes, definiu-se que a geometria do componente o modo com que se daria a movimentação de suas partes deveriam ser definidas segundo a correlação entre as diferentes possibilidades de configuração do elemento, de modo isolado, e com estes trabalhando em diferentes grupos. Sendo assim, durante a pesquisa decidiu-se explorar não apenas os dados coletados na etapa de levantamento e passou-se também a investigar outras maneiras de gerar formas geométricas, em que a movimentação das partes do componente não se desse de modo complicado. O objetivo final era obter, mesmo com poucos recursos, um protótipo físico funcional. Sendo assim, foram utilizadas como fonte de inspiração para a definição de um protótipo métodos de dobragem de papel e a deformação de materiais.

O primeiro método explorado durante a elaboração dos protótipos geométricos foi o Miura fold (Nishiyama, 2009). Este sistema de dobragem foi desenvolvido pelo astrofísico japonês Korio Miura com objetivo de reduzir a área de uma superfície segundo um padrão de dobragens que cria uma tesselação formada por paralelogramos. O origami Miura é uma estrutura bem conhecida, utilizada inicialmente em painéis solares para uso no espaço ou para a dobragem de mapas.

Além da utilização de métodos de dobragem de papel como fonte de geração de um protótipo, também foi estudada a possibilidade de deformação de materiais, permitindo assim o controle de incidência de luz e de ventilação por meio de variações na temperatura e umidade (Klooster, 2009). Addington and Schodek (2009) definem materiais inteligentes como sistemas que incorporam funções tecnológicas permitindo respostas ao ambiente por meio de mudanças em suas propriedades internas ou por meio da ação externa. Ambos definem como características destes materiais a resposta imediata a mais de um estado ambiental, por meio de ação própria e independente, e direcionada a eventos locais. Superfícies inteligentes podem ter um papel importante no desenvolvimento de edificações com envelopes inteligentes e adaptativos. Uma de suas características mais relevantes é sua habilidade em transformar suas propriedades físicas e formais, ou trocar energia sem requerer uma fonte externa de energia. Os experimentos de cobertura responsiva desenvolvidos pela arquiteta Dóris Sue, podem ser citados como exemplo de aplicação destes princípios. Neste caso, a arquiteta faz uso de peles metálicas que apresentam a capacidade de abrir seus poros, dependendo da temperatura ambiental.
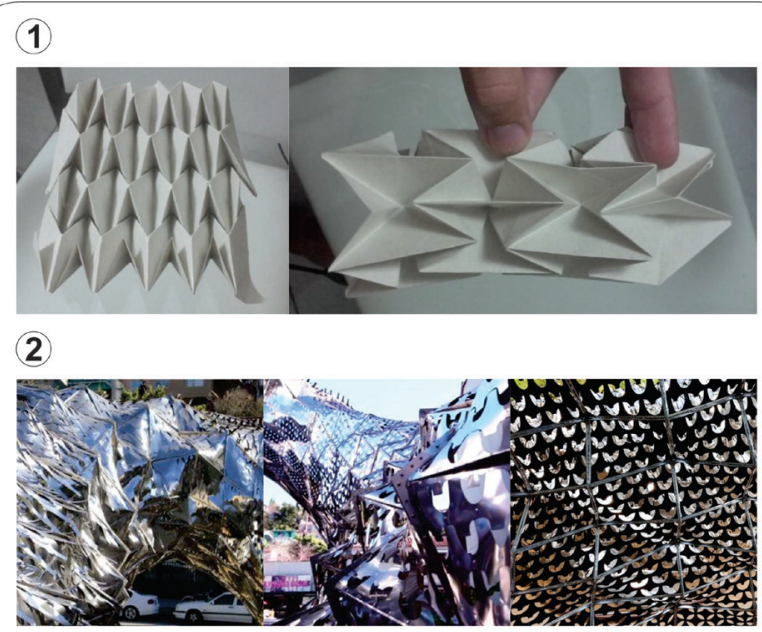

(3)

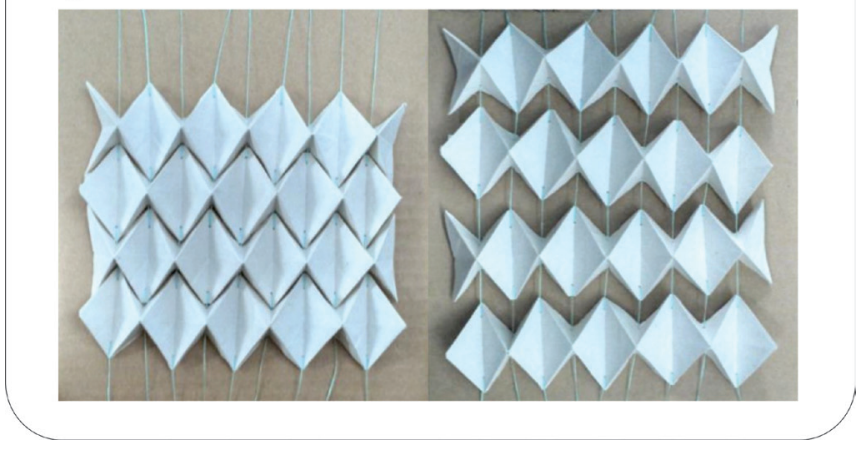

Figura 3: (1) Modelo de papel construído utilizando-se a técnica de dobragem de papel desenvolvida por Korio Miura. (2) Cobertura projetada com "materiais inteligentes" pela arquiteta Doris Sung. (3) Testes de movimentação de partes de modelos. Fonte: elaboração própria.

Neste caso foi avaliada a alteração da forma em tecidos com propriedades elásticas. Como a intenção era que o sistema associasse fatores ambientais à presença do usuário e a atividade que poderia estar sendo desenvolvida no espaço, optou-se por combinar a deformação dos materiais à ação de atuadores. Como resultado, uma das características básicas dos 
materiais inteligentes não foi absorvida ao longo da pesquisa.

Esta etapa de investigação envolveu o desenvolvimento de modelos físicos em papel, como também digitais, criados em ambientes de modelagem paramétrica visual, tais como o Grasshopper. Estes estudos possibilitaram aos pesquisadores explorar diferentes modelos e identificar as restrições e barreiras que poderiam ser encontradas, principalmente em relação à etapa de automação do sistema.

\section{Etapa 3 - Elaboração de modelos físicos dos protótipos}

Apesar dos ambientes de modelagem atualmente permitirem a criação de formas tridimensionais de elevada complexidade, buscou-se criar protótipos que apresentassem padrões geométricos simples e evitou-se o uso de superfícies de dupla curvatura. O objetivo final era construir um modelo físico funcional, mesmo sem acesso a equipamentos de prototipagem a fabricação.

Os modelos físicos foram elaborados com o objetivo de realizar testes preliminares e verificar as dificuldades que poderiam ser enfrentadas em relação à automatização de seus movimentos. Também, nesta etapa passou-se a investigar os diferentes tipos de atuadores e motores elétricos (Servo-motores, motores de passo e corrente continua) que possibilitariam deslocar as partes dos protótipos estudados. Como objetivo da pesquisa era tentar buscar a redução de custos e evitar a dificuldade de aquisição de componentes, foi estudado, por exemplo, a utilização de motores de passo presentes em componentes eletrônicos abandonados na própria Universidade Federal de Pernambuco.

A partir dessa etapa da pesquisa optou-se por utilizar micro servo motores (HXT9001) como atuadores por estes serem de fácil aquisição, custo baixo e simples instalação. Motores de passo dependem de um maior conhecimento de eletrônica para funcionarem de forma adequada e, a partir de motores de corrente contínua, não é possível controlar o giro do eixo de forma precisa, impossibilitando interromper o movimento em ângulos pré-definidos.

Tendoconhecimentodas restriçõesem relaçãoageometria e do atuador a ser utilizado no protótipo foram elaborados modelos físicos utilizando diferentes materiais, tais como papel, balsa e papelão. Após construídos estes foram testados de diferentes maneiras com o objetivo de compreender qual poderia trazer maior benefício em relação aos parâmetros pré-definidos (temperatura, umidade e a luminosidade). Por exemplo, os modelos criados segundo técnicas de dobragem de papel foram divididos em módulos diferentes. A partir dos diferentes módulos testou-se variações em relação ao posicionamento de suas partes. Neste caso, verificou-se pouca flexibilidade em relação a proteção da incidência de luz solar direta ou na possibilidade de compor diferentes padrões de desenho em uma fachada.

1 Tamanho 21x12x22 mm; voltagem: 3v 6v; peso: 9 gramas; velocidade: $0.12 \mathrm{sec} / 60$; torque: $1.6 \mathrm{~kg}-\mathrm{cm}$; temperatura de trabalho: $-30 \circ \mathrm{o} \sim 60 \mathrm{oC}$.
A partir dos resultados foram selecionados dois protótipos a serem implementados em um ambiente de modelagem paramétrica. O primeiro deles, baseado no processo de dobragem de papel. O segundo que envolvia a deformação de fitas por meio da torção de um material.

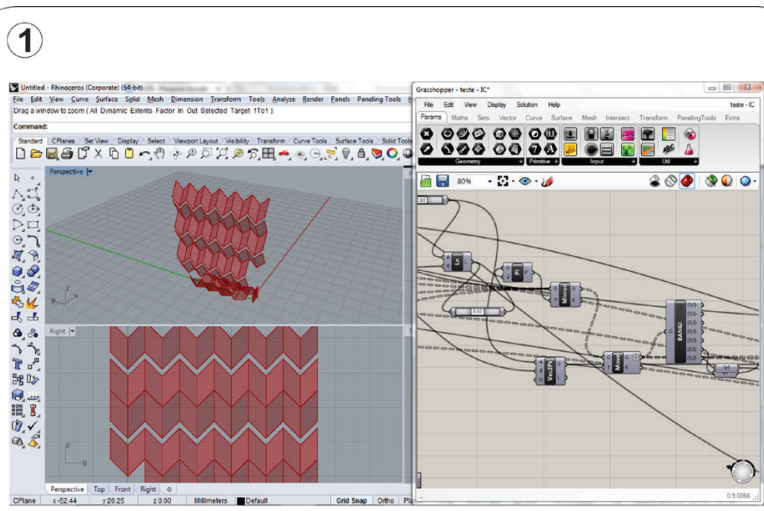

(2)

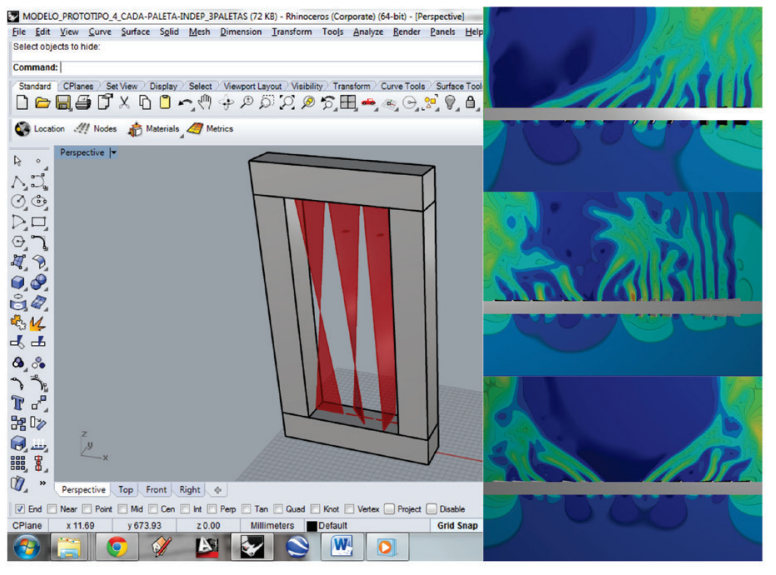

Figura 4: (1) Protótipo elaborado por técnica de dobragem, implementado em Grasshopper. (2) Protótipo com torção de fitas e simulações em plataformas para análise de ventilação. Fonte: elaboração própria.

Etapa 4 - Teste em ambiente de modelagem paramétrica e em aplicativos de ventilação e iluminação

Nesta etapa da pesquisa foram utilizadas como plataforma de modelagem o aplicativo Rhinoceros e o editor de algoritmos visual Grasshopper. O objetivo era criar modelos paramétricos com a intenção de simular qual poderia ser o comportamento do protótipo físico. As simulações foram realizadas segundo duas configurações diferentes. Na primeira, cada módulo era implementado e estudado com o objetivo de avaliar como se daria a alteração da sua geometria levando em consideração intervalos numéricos similares aos dos parâmetros ambientais a serem estudados. Por exemplo, caso a temperatura aumenta, qual a proporção do componente deve se abrir para permitir a ventilação. Se a luminosidade diminui no ambiente interno, qual também deverá ser a proporção de abertura permitindo 
assim a entrada de luz natural.

Além do estudo da movimentação das partes, os modelos paramétricos foram testados com o objetivo de avaliar o seu comportamento em relação à fatores ambientais. Nesta fase, 0 módulo de extensão Geco, para Grasshopper, foi utilizado para criar uma conexão com o aplicativo de análise de performance ambiental Autodesk Ecotect. A partir dele foi possível avaliar a radiação solar que incidiria sobre as partes do modelo. Também, por meio do plug-in DIVA foi analisada a variação da intensidade luminosa e do aplicativo Autodesk Flow Design a alteração do fluxo de vento (ver figura 3).

\section{Etapa 5 - Correlação entre sensores e modelos digitais}

Para capturar as informações ambientais foram instalados junto dos modelos físicos três sensores: o de temperatura com precisão calibrada de $1^{\circ} \mathrm{C}$ (LM35), o de umidade que abrange um intervalo de $20 \%$ a $50 \%$ (DHT11) e o de luminosidade cuja resistência varia conforme a quantidade de luz (LDR). Estes foram conectados a uma placa de Arduino que processou os dados coletados no ambiente e os enviou ao modelo paramétrico. Deste modo foi possível realizar a correlação direta entre os sensores coletando dados ambientais, em uma situação real, e o modelo digital. A sequência de aplicativos utilizados é apresentada no quadro abaixo. A figura 5, parte 1, mostra o sensor de temperatura sendo testado.

\begin{tabular}{|c|l|l|l|}
\hline Fase & Componente & Objetivo \\
\hline 1 & Arduino & $\begin{array}{l}\text { Plataforma de } \\
\text { prototipagem } \\
\text { eletrônica }\end{array}$ & $\begin{array}{l}\text { Processa os dados } \\
\text { coletados pelos } \\
\text { sensores }\end{array}$ \\
\hline 2 & Gobetwino & $\begin{array}{l}\text { Aplicativo que } \\
\text { coleta ou envia } \\
\text { dados pelas } \\
\text { portas seriais }\end{array}$ & $\begin{array}{l}\text { Utilizado como } \\
\text { ponte entre } \\
\text { o Arduino e } \\
\text { o ambiente } \\
\text { Processing IDE }\end{array}$ \\
\hline 4 & $\begin{array}{l}\text { Processing } \\
\text { IDE }\end{array}$ & $\begin{array}{l}\text { Linguagem de } \\
\text { programação de } \\
\text { código aberto } \\
\text { e ambiente de } \\
\text { desenvolvimento } \\
\text { integrado }\end{array}$ & $\begin{array}{l}\text { Utilizado para } \\
\text { processar os dados } \\
\text { coletados pelo } \\
\text { Gobetwino }\end{array}$ \\
\hline 5 & GHOWL & $\begin{array}{l}\text { Conjunto de } \\
\text { componentes } \\
\text { que estendem } \\
\text { a habilidade do } \\
\text { Grasshopper } \\
\text { de comunicar } \\
\text { e trocar } \\
\text { informações com } \\
\text { outras aplicações } \\
\text { e dispositivos } \\
\text { físicos }\end{array}$ & $\begin{array}{l}\text { Coletar os dados } \\
\text { processados pelo } \\
\text { Processing e dire- } \\
\text { cioná-lo ao mod- } \\
\text { elo paramétrico }\end{array}$ \\
\hline
\end{tabular}

Quadro 1: Quadro apresentando os aplicativos segundo a sequência de transferência dos dados até os modelos paramétricos. Fonte: elaboração própria.
Etapa 6 - Elaboração de protótipos físicos funcionais do modelo

Apesar de diferentes modelos físicos e digitais terem sido desenvolvidos em cada uma das etapas da pesquisa, apenas um foi selecionado um para a realização de testes. Os modelos elaborados a partir da dobragem de papel apresentavam um padrão de movimentação das partes mais complexo, com deformações em relação aos eixos X, Y e Z. Já as possibilidades estudadas a partir da deformação do material, segundo alterações na temperatura e umidade, dependiam de materiais mais difíceis de adquirir.

Como resultado, um protótipo final foi elaborado levando em consideração a deformação do material, contudo a partir movimentação causada por atuadores. A configuração do protótipo é apresentada na figura 6. Nele, são movimentadas três fitas largas de poliéster posicionadas paralelamente, na horizontal. Cada uma de suas pontas é fixada a um servo motor acoplado em uma esquadria de alumínio de formato retangular, sendo que estas podem se mover separadamente, promovendo, por meio da torção, diferentes gradientes de circulação de ar e de entrada de luz no ambiente.

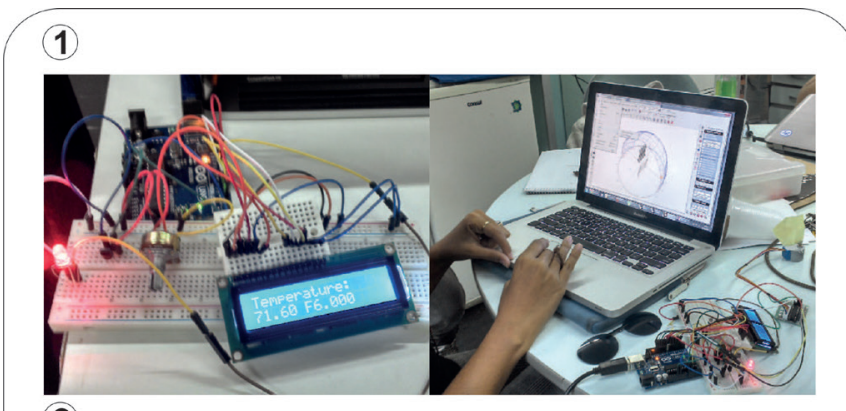

(2)

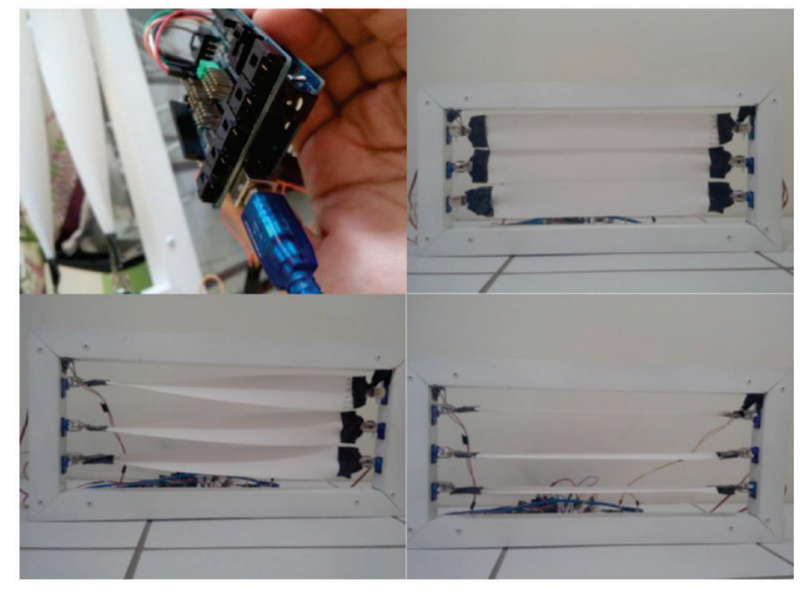

Figure 5: (1) Correlação entre o sensor de temperatura e o modelo digital através da placa de arduino e diversas conexões (2) Testes no protótipo desenvolvido na etapa final da pesquisa. Fonte: elaboração própria.

A figura 5 apresenta o protótipo final em funcionamento com as suas partes moveis em diferentes posições. O mesmo código utilizado para controlar o sensor de temperatura e 
enviar os dados ao modelo digital foram utilizados no protótipo físico. Como resultado, as respostas obtidas no mundo real foram muito semelhantes as que foram testadas na fase anterior. Portanto, realizar a ponte entre o sensor, além de não ser um processo complexo, colaborou na compreensão do que iria ocorrer caso um protótipo fosse construído. A figura 5, parte 2, mostra os testes do protótipo final.

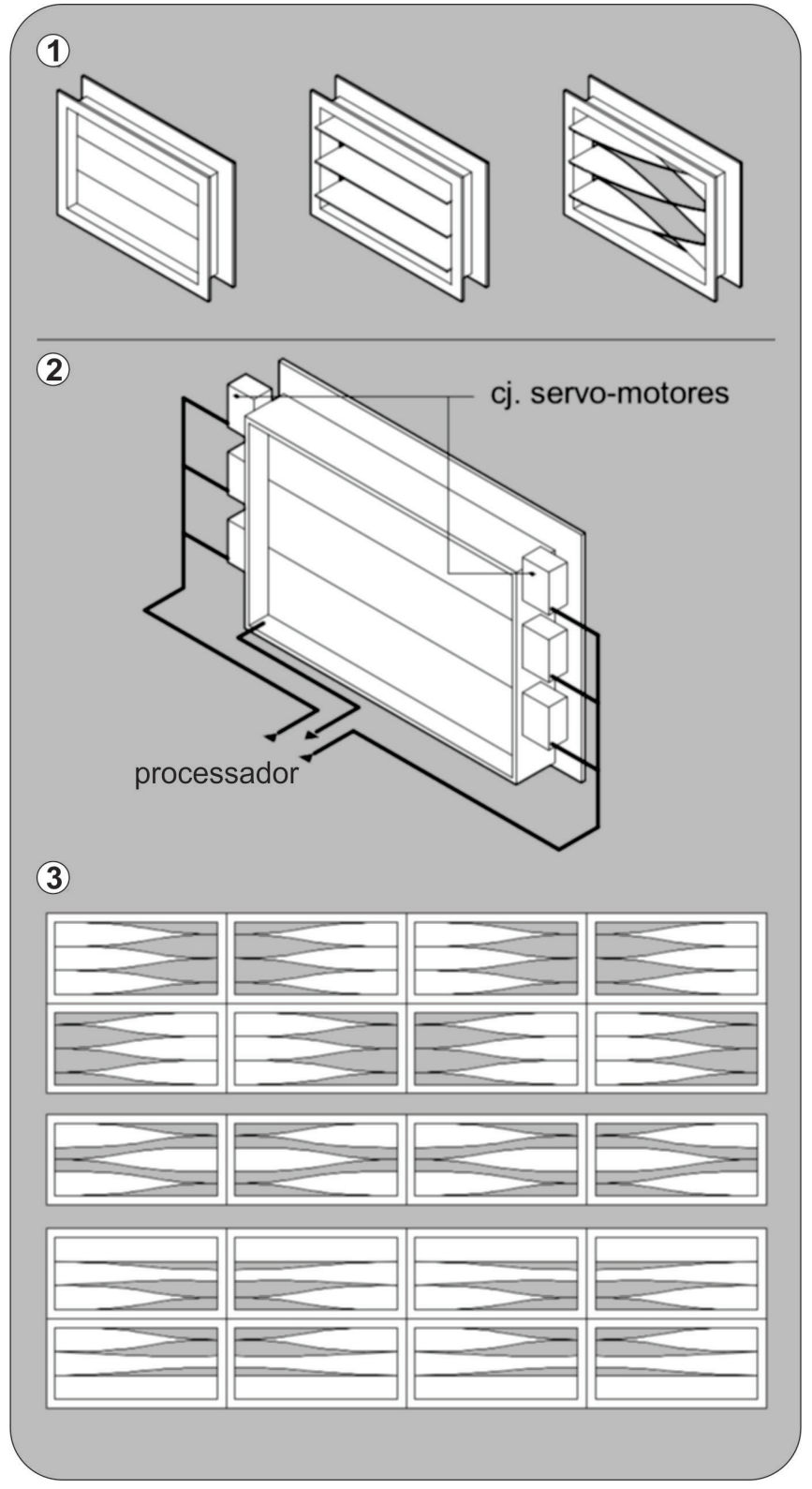

Figura 6: Testes de movimentação de partes de modelos elaborados a partir de dobragem de papel. Neste caso, o modelo foi subdividido para buscar alternativas para deslocar conjuntos de modo mais simples. Fonte: elaboração própria.

\section{Resultados}

Apesar de terem sido desenvolvidos protótipos digitais com uma geometria complexa, o protótipo físico final foi elaborado com materiais simples e com reduzida complexidade geométrica. Optou-se por esta estratégia devido a restrições em relação a obtenção de materiais e equipamentos adequados confecção do modelo e sua automação. Contudo, apesar do componente em si apresentar uma geometria simples, quando trabalhando em conjunto há uma grande possibilidade de composições pelos diferentes níveis de movimentação. Por exemplo, cada servo-motor pode funcionar de forma independente, com ângulos variando de 10 em 10 graus e podem ser pré-programados para se dispor em diferentes padrões, mesmo com parâmetros iguais de temperatura e luminosidade, etc.

Os protótipos elaborados por outros pesquisadores, utilizando o conceito de materiais inteligentes, baseiam-se na alteração da forma em um processo independente. Ou seja, não há como controlar sua modificação, o que torna impossível controlar seu padrão de funcionamento. Por outro lado, o protótipo desenvolvido na pesquisa depende de diferentes mecanismos para funcionar e de uma fonte de energia.

\section{Discussão}

Além do objetivo de estudar anteparos de proteção de fachada responsivo, a pesquisa visava investigar a possibilidade de introdução de conceitos relacionado a modelagem paramétrica, programação e robótica em um curso de arquitetura tradicional, onde o ensino se baseia na prancheta, seja esta digital ou não. Uma faculdade em que o computer aided design ainda é visto como uma ferramenta de desenho.

A contribuição desta pesquisa para o conhecimento não está necessariamente relacionada apenas ao produto final (protótipo), mas no processo em que foi desenvolvido e a as circunstâncias que envolviam o projeto. A pesquisa foi realizada por dois alunos de iniciação científica, graduandos do terceiro ano do curso de arquitetura, que não tinham conhecimento das diferentes ferramentas utilizadas. A partir de um processo de exploração aprenderam conceitos de programação, encontraram as ferramentas de análise mais adequadas para testar o protótipo e desenvolver um modelo físico funcional. Mesmo sem ferramentas de prototipagem e fabricação, que apresentam um custo relativamente alto, foi possível abordar importantes aspectos e conhecimentos de computer aided design. A lista abaixo apresenta os aplicativos utilizados durante a investigação:

1. Rhinoceros: Plataforma de modelagem 3D.

2. Grasshopper: Editor de algoritmos visual do Rhinoceros que possui como funcionalidade principal criar modelos paramétricos;

3. DIVA: software de analise térmica, luz do dia e radiação solar, para uma abrangente análise do comportamento do modelo 3D do protótipo.

4. Ecotect: ambiente para análise de conforto em projeto de edificações;

5. Autocad 2013: Ferramenta para desenhos técnicos. 
6. IDE Arduino: Ambiente de desenvolvimento da placa Arduino UNO R3;

7. IDE Processing: ambiente de desenvolvimento para as artes eletrônicas e visuais;

8. Gobetwino: Aplicativo que coleta ou envia dados pelas portas seriais;

9. Flow design:é um túnel de vento 3D virtual para a simulação de fluxo de ar para projetos de design, do edifício e da cidade.

Os aplicativos utilizados durante o processo de pesquisa foram obtidos nas versões de teste, livre ou estudantil. Os hardwares foram adquiridos com o passar da pesquisa, através de websites especializados em micro controladores e compras avulsas pela internet, visto que em Recife, não existem fornecedores para esses materiais. A tabela abaixo (quadro 2) apresenta os materiais utilizados durante a pesquisa para a implementação do protótipo.

Apesar da simplicidade o protótipo elaborado possibilita inúmeras configurações. Em etapas futuras pretende-se testar diferentes algoritmos, tornando assim o sistema responsivo a fatores humanos. Por exemplo, identificando a presença de usuários no ambiente e as atividades que estes estão desenvolvendo.

\begin{tabular}{|c|c|c|}
\hline Quant. & Material & Custo (R\$) \\
\hline 1 & $\begin{array}{l}\text { Placa micro controladora, } \\
\text { Arduino UNO R3 }\end{array}$ & 50,00 (unidade) \\
\hline 1 & $\begin{array}{l}\text { Sensor Shield para } \\
\text { Arduino }\end{array}$ & 23,00 (unidade) \\
\hline 6 & Micro servo moto 9g & 15,00 (unidade) \\
\hline 1 & Protoboard 830 furos & 17,90 (unidade) \\
\hline 2 & Sensores de luz LDR & 7,95 / conj. com 10 \\
\hline 1 & $\begin{array}{l}\text { Fios Jumpers machos e } \\
\text { fêmeas }\end{array}$ & 13,95 / conj. com 65 \\
\hline 2 & Resistores de $10 \mathrm{~K}$ & 13,95 / kit c/ 200 \\
\hline 2 & Resistores de 0,22K & $\begin{array}{r}\text { Incluso no kit } \\
\text { acima }\end{array}$ \\
\hline 1 & $\begin{array}{l}\text { Fonte de alimentação ATX } \\
\text { Fortrek, } 200 \mathrm{~W}\end{array}$ & 49,00 (unidade) \\
\hline 1 & $\begin{array}{l}\text { Fita elástica de ( } 88 \% \\
\text { polyester, } 12 \% \text { spandex) } \\
\text { branca, } 5 \mathrm{~cm} \text { de largura }\end{array}$ & 5,50 o metro \\
\hline 6 & Jacarés para suspensórios & 3,50 (unidade) \\
\hline 1 & Fita isolante preta & 4,50 (unidade) \\
\hline 1 & Esquadria de alumínio & Material doado. \\
\hline \multicolumn{2}{|c|}{ Custo total } & $\mathrm{R} \$ 204,25$ \\
\hline
\end{tabular}

Quadro 2: Custos dos Hardwares e materiais para construção do protótipo. Fonte: Elaboração própria.

\section{Agradecimentos}

Agradecemos a Coordenadoria de Aperfeiçoamento de Pessoal de Nível superior (CAPES) pelo financiamento da pesquisa por meio de uma bolsa de iniciação científica. Agradecemos ao orientador Carlos Eduardo Verzola Vaz por abrir mão da autoria do artigo para permitir que orientandos e colaboradores estivessem todos presentes.

\section{References}

Addington, M., Schodek, D. (2009). Smart Materials. Berlin: Birkhauser T. press.

Archdaily. (2013, Janeiro 28). As Torres Al Bahar e sua fachada sensível, por Aedas Architects. Acesso em Novembro de 2013 em http://www.archdaily.com.br/br/01-93779/as-torres-albahar-e-sua-fachada-sensivel-por-aedas-architects.

Archdaily. (2013, Agosto 5). Escritórios do Conselho de Melbourne 2 (CH2) / DesignInc Acesso em Maio de 2014 em http://www.archdaily.com.br/br/01-132298/escritorios-doconselho-de-melbourne-2-ch2-slash-designinc .

Archdaily. (2015, Janeiro 30). SDU Campus Kolding / Henning Larsen Architects. Acesso em Maio de 2015 em http://www. archdaily.com/590576/sdu-campus-kolding-henninglarsen-architects E-architect. (2008, Junho 8). Kiefer Technic Showroom. Acesso em Maio de 2015 em http://www.earchitect.co.uk/austria/kiefer-technic-showroom.

Barros H., Lombardo, M. (2013). Zoneamento climático urbano da cidade do Recife: uma contribuição ao planejamento urbano. Revista GEOUSP: Espaço e Tempo, São Paulo, 33, pág. 187-197.

Beesley, P., Hirosue, S.; Ruxton, J., Trankle, M., Turner, C. (2006). Responsive Architectures: Subtle Technologies. Riverside: Architectural Press.

Bittencourt, L., Cândido, C. (2010) Ventilação natural em edificações. Procel Edifica.

D'alecon, R. (2013, Agosto). Fachadas transparentes: sistemas activos y passivos. ARQ, Santiago, 84, p. 1-5.

Fox, M., Yeh, B. (1999) 1st International Workshop on Managing Interactions in Smart Environments. MANSE conference proceedings, Springer London, Dublin, 1, p. 91-103. Freitas, R. (2008) Entre mitos e limites - as possibilidades do adensamento construtivo face à qualidade de vida no meio urbano. Recife: EDUFPE.

Gjerde, E. (2008). Origami Tessellations: Awe-Inspiring Geometric Designs. Massachusetts: A K Peters Press.

Henriques, G. C. (2012) TetraScript: a responsive pavilion, from generative design to automation. International Journal in Architectural Computing, Londres: 10 (01), p. 87-104. Instituto Nacional de Meteorologia (INMET) (2013) Normais climatológicas do Brasil 1961-1990. Acesso em: Janeiro em http://www.inmet.gov.br/portal/index.php?r=clima/ normaisclimatologicas.

Klooster, (2009), Smart Surfaces and their Application in Architecture and Design, Berlin: Birkhauser T. press, p.5 Negroponte, N. (1975). Soft Architecture Machines. Cambridge: MIT Press.

Nishiyama, Y. (2009 May 15). Miura Folding: Applying Origami to Space Exploration. Osaka Keidai ronshu, 60(1), 17-24. 
Oliveira, N. C. F. (2013). Superfícies abstratas: o elemento cerâmico como textura na arquitetura moderna brasileira IV seminário docomomo sul. Pedra, barro e metal. Norma e licença na arquitetura moderna do cone sul americano, 1930/70.

Poulsen, E. S, Jørgen, H. A, Jensen, O. B. (2013) Responsive city lighting: perspectives from architecture and the public lighting industry. In: Conference on Human Factors in
Computing Systems. 1st CHI conference proceedings changing perspectives, Paris, 2013.

Souza, H. M. P. (2012). O conforto ambiental na arquitetura colonial brasileira: heranças muçulmanas Architecton revista de arquitetura e urbanismo. 02 (02).

Vieira, A., Borba, C., Rodrigues, J. (2012). Cobogó de Pernambuco. Recife: J. Rodrigues. 